Geopolítica(s) Revista de estudios sobre espacio y poder ISSN: 2172-3958

http://dx.doi.org/10.5209/GEOP.58129

\title{
Espacio nacional y espacio global del capitalismo ${ }^{1}$
}

\author{
Álvaro García Linera ${ }^{2}$ \\ Recibido: 11 de octubre de 2017 / Aceptado: 22 de octubre de 2017
}

Resumen. A partir de la distinción marxista sobre los valores de la mercancía, en este artículo se intenta establecer la diferencia entre espacio nacional y espacio global. El espacio nacional se sustentaría en el valor de uso, mientras que el espacio global resultaría de la intercambiabilidad de las mercancías, de su valor de cambio. Por su propia naturaleza cíclica, el proteccionismo y el libre comercio se alternan en el capitalismo, el primero apela al Estado nacional, mientras que el segundo lo hace a la geografía mundial. La crisis del neoliberalismo, vinculada a la crisis cíclica del libre comercio, permitiría el desarrollo de resistencias efectivas al sistema en los eslabones débiles del sistema capitalista, como en América Latina.

Palabras clave: globalización; proteccionismo estatal; libre comercio; desigualdades internacionales; crisis del neoliberalismo.

\section{[en] National Space and Global Space under Capitalism}

\begin{abstract}
Drawing on the Marxist notion of commodity value, this article seeks to establish the difference between national space and global space. The idea of national space is anchored in the notion of use-value, whereas the idea of global space is bound to the exchange of commodities (exchangeuse). Alternating between protectionism and free market, the cyclical nature of capitalism introduces a tendency to accentuate either the national space or the global space. Linked to cyclical crises in the free market dynamics, the crisis of neoliberalism enables the development of effective resistances to the system in the weak areas of the capitalist system such as Latin America.
\end{abstract}

Keywords: globalization; state protectionism; free market; international inequalities; neoliberalism crisis.

\section{[pt] Espaço nacional e espaço global do capitalismo}

Resumo. A partir da distinção marxista sobre os valores da mercadoria, neste artigo se busca estabelecer a diferença entre espaço nacional e espaço global. O espaço nacional se sustentaria no valor de uso, enquanto o espaço global resultaria da fungibilidade entre as mercadorias, de seu valor de troca.

1 Conferencia magistral pronunciada el 27 de abril de 2017 en el XVI Encuentro de Geógrafos de América Latina (EGAL 2017), que tuvo lugar en el hotel Real Plaza Convention (La Paz, Bolivia), organizado por el Instituto de Investigaciones Geográficas (IIGEO) de la Carrera de Ingeniería Geográfica de la Universidad Mayor de San Andrés (UMSA). Disponible en URL: $<$ https://www.youtube.com/watch?v=X8GfFNKV9nA>. Trascripción: Ana Santamarina.

2 Vicepresidente del Estado Plurinacional de Bolivia E-mail: rgaagl@gmail.com 
Por sua própria natureza cíclica, o protecionismo e o livre comércio se alternam no capitalismo, o primeiro apela ao Estado nacional, ao passo que o segundo, à geografia mundial. A crise do neoliberalismo, vinculada à crise cíclica do livre comércio, permitiria o desenvolvimento de resistências efetivas ao sistema nos enlaces frágeis do sistema capitalista, como na América Latina.

Palavras-chave: globalização; protecionismo estatal; livre comércio; desigualdades internacionais; crise do neoliberalismo.

Sumario. Introducción. 1. La mercancía, los espacios nacionales y el espacio global. 2. Proteccionismo y libre comercio. 3. Los abismos espaciales de la riqueza y el poder en la globalización. 4. La organización espacial del capitalismo: la crisis del neoliberalismo. Conclusiones y reflexiones de futuro. Bibliografía.

Cómo citar: García Linera, Álvaro (2017) "Espacio nacional y espacio global del capitalismo". Geopolítica(s). Revista de estudios sobre espacio y poder, vol. 8, núm. 2, 159-176.

\section{Introducción}

En un encuentro al que me invitaron los compañeros de Geografía, recientemente, introduje un concepto que era la "topología del Estado" para estudiar cómo es que el Estado, a lo largo de los siglos, ha construido la significación y la ocupación del espacio amazónico. Me fijé fundamentalmente en la Amazonía boliviana e introduje esta categoría para ver cómo la geografía es un espacio de significaciones y, por lo tanto, de lucha, de interpretaciones sociales que se disputan no solo la manera dominante de imaginar el territorio, sino, además, de ocuparlo, de usarlo y de ubicarse históricamente en él. Por consiguiente, si bien la geografía tiene una condición natural objetiva, la manera en cómo la geografía es interiorizada por la sociedad, por los gobiernos, por los pueblos, por las personas, por las naciones y las clases sociales, va a variar dependiendo de los resultados de esas luchas políticas. No existe una sola lectura práctica de la geografía. Hay una única condición material de la geografía, pero existen múltiples significaciones de esa condición material; también, múltiples y diversas maneras de asumir, interpretar, absorber, utilizar y transformar esa geografía y la naturaleza en la geografía.

Y el día de hoy, recogiendo esta manera de abordar el espacio, quisiera trabajar unas hipótesis sobre el espacio global, en lo que podríamos denominar una "topología de la globalización”.

\section{La mercancía, los espacios nacionales y el espacio global}

La forma en cómo la riqueza se presenta hoy en el mundo capitalista es como un "cúmulo de mercancías" nos dice Marx (1987: 6) en el primer capítulo de su libro El capital. Empresas, comercios, países y continentes se organizan socialmente, contabilizan sus logros, destacan sus capacidades, etc., en torno a las mercancías, incluida su "forma acabada" que es el dinero. Esto hace de la mercancía la "forma celular económica" de la sociedad moderna y en su núcleo se halla contenido la información clave de las formas más desarrolladas y complejas como son los Estados, los mercados, los territorios y el espacio global capitalista. 
Esta forma de la riqueza moderna, la mercancía, tiene dos componentes sociales: su cualidad de uso, su utilidad, que Marx llama el valor de uso; y el segundo componente, su cualidad de intercambiabilidad, la manera de acceder a él, el valor de cambio. Un pan, un televisor, un celular, un libro, un automóvil tienen determinada utilidad que satisface algún tipo de necesidad o requerimiento humano. Un pan alimenta, un televisor informa o distrae, un celular comunica y transmite, un automóvil transporta, etc. Esta capacidad de alimentar, informar, transmitir, transportar y, demás, de alguna cosa creada por el trabajo humano, es el valor de uso de la mercancía y se trata de una cualidad adherida a la naturaleza misma del objeto. Dime para qué sirve tal o cual cosa y te diré cuál es su valor de uso. Pero, para acceder a ese celular, para acceder al uso de ese televisor o ese automóvil y poder utilizar la utilidad que posee, las personas no pueden ir simplemente a una tienda y sacarse el televisor o el pan. Deben pagar por el pan, deben pagar por el celular, determinada cantidad de dinero. A esta cantidad de dinero, o de valor, que una persona paga por obtener la propiedad de determinado producto para usufructuarlo, Marx le denomina el valor de cambio. No importa cuanta sea la necesidad de una persona respecto a un determinado producto, si no paga su precio, su "valor", no podrá llegar hasta el producto requerido y darle vida a su utilidad, a su valor de uso. Esta cualidad del valor de cambio de las mercancías, del "precio" que tienen y que está contenido en el mismo objeto, regula el modo de acceso o intercambiabilidad de las cosas, de las mercancías, en la sociedad moderna.

El mundo moderno es, entonces, un escaparate de millones de mercancías portadoras de algún tipo de utilidad social, pero solo son accesibles, utilizables, si uno paga su valor de cambio. Esta doble naturaleza social de las riquezas modernas, valor de uso y valor de cambio, utilidad y precio, son por tanto la cualidad fundamental inseparable de todos los productos del trabajo que rodean nuestra cotidianidad.

Ahora bien, pero esta cualidad de consumo de las mercancías, su valor de uso, nos remite al sistema de necesidades de una sociedad. Hoy tenemos en las tiendas objetos que hace miles de años atrás seguramente no tendrían ningún sentido o utilidad. Por ejemplo, un chip o una bombilla de electricidad, en tiempos de la Grecia clásica, no satisfaría ninguna necesidad y sería considerada parte de la basura desechable. Igualmente, una tabla de cálculo sumerio esculpida en piedra, más allá del interés de un museo o de un coleccionista de antigüedades, no sería una mercancía exitosa en ninguna tienda de artefactos de cálculo electrónico. La utilidad de las cosas depende, entonces, de un entorno social, del tipo de apetencias, expectativas y esquemas de consumo que determinada sociedad ha creado en la historia. Cosas útiles hoy, dejarán de serlo mañana, y cosas inútiles hoy, posiblemente serán muy útiles después, dependiendo de cómo es que la sociedad ha ido estructurando culturalmente sus consumos y su horizonte de expectativas.

A esta determinación social del mundo de las necesidades es que le llamamos el sistema de necesidades, y está claro que es fundamentalmente una construcción cultural territorializada que toma en cuenta las capacidades laborales que tiene una sociedad, el cúmulo de apetencias colectivas despertadas, las influencias externas y la capacidad de adecuar sus expectativas de consumo a sus capacidades reales de satisfacerlas. 
Esta adecuación de las expectativas de consumo, que podrían ser infinitas, a las capacidades para satisfacerlas - que son limitadas - , es lo que delimita el sistema de necesidades de una sociedad y lo que además estructura el orden social territorial, es decir, la correspondencia cotidiana entre la norma, la ley, el régimen de propiedad y el comportamiento moral, lógico e instrumental de los individuos. Y esa es una tarea de adhesión cultural y cohesión social territorializada que en el capitalismo ha recaído, recae y, necesariamente, seguirá recayendo en el Estado.

El que las personas no tomen por asalto las tiendas para acceder al objeto mercantil de su deseo, y si lo hacen, sean castigados; el que aprendan destrezas para usar y adquieran conocimiento para valorar determinadas cosas; el que cultiven disposiciones de acatamiento íntimo a la forma en que el mundo está organizado y a cómo desenvolverse exitosamente en él; el que aprecien determinadas características materiales de las cosas por encima de otras; el que jerarquicen determinados usos sobre otros, determinados bienes sobre otros, etc., todo esto que ponen en marcha cada día el engranaje del mundo de las mercancías, depende de la educación escolar y familiar; dependen del sistema de normas y de ideas prevalecientes en los sistemas de comunicación; dependen de las puniciones amenazantes y los reconocimientos de legitimación que en gran medida los monopoliza el Estado, o al menos, los organiza y delimita.

De esta manera, la realización del valor de uso de la mercancía en la sociedad moderna capitalista está regulada, producida y validada en el espacio territorial nacional-estatal. Es como si en el contenido material de la riqueza, en su cualidad objetiva de utilidad, se comprimiera la historia y la cultura acumulada para hacer de ese objeto un objeto útil para el que lo observa y lo desea. De ahí que Marx señale que los diversos aspectos de la utilidad de las cosas y, "en consecuencia, de los múltiples modos de usar las cosas, constituye un hecho histórico" (1987: 44).

Así, cuando la persona se confronta con la mercancía, para que estalle la utilidad en ella y se gatille el acto de intercambiabilidad, de compra y de uso, tiene que haber, previamente, una sintonía estructural entre el mundo de percepciones sociales de la persona y el mundo de cualidades objetivas, socialmente producidas, de las cosas. Y eso solo lo logra el sistema cultural territorial del Estado, o de los Estados por medio de la construcción del sistema de necesidades que depende de la cultura, de la cohesión social y la constante adecuación de las necesidades personales a las posibilidades sociales. En la medida en que este subsuelo cognitivo alumbra la utilidad social del objeto que está al frente de la persona, recién comienza la historia de la cosa, del producto del trabajo como mercancía portadora de un valor de cambio para su intercambiabilidad. El que luego el valor de cambio domine la historia social, incluida la construcción permanente de la sintonía estructural entre las percepciones humanas de lo que se considera socialmente útil y la cualidad material de la mercancía, no elude que este proceso de la construcción social de la utilidad de las cosas tenga que renovarse cada día de manera territorializada en los esquemas cognitivos y sensibles de las personas.

Entonces es en el valor de uso de la mercancía, y esta es mi hipótesis de trabajo, donde está anidada la primera dimensión geográfica del capitalismo: el espacio nacional. Porque es en el espacio nacional donde se construye cohesión social, donde se construye cultura, donde se produce correspondencia entre saberes prácti- 
cos de las personas y utilidades materiales de las cosas y, por lo tanto, donde se forma el conjunto de necesidades colectivas de la sociedad.

Pero el otro componente de este objeto simple y fundamental de la sociedad moderna, la mercancía, es el valor de cambio, y el valor de cambio nos remite a las formas de intercambiabilidad. Pero, ¿qué nos dice Marx al respecto? Que lo que diferencia el capitalismo de otras sociedades donde también se producen objetos es que el productor directo produce para alguien "que no es su poseedor" (Marx, 1987: 999), para alguien que no es ni el productor directo de esa mercancía ni el propietario de esa mercancía. Y el "no poseedor" que ha de realizar la utilidad del objeto producido puede ser alguien de la región, del país, del continente o del mundo mismo.

Esto significa que el planeta entero es el espacio de realización de la intercambiabilidad de la mercancía o, si se prefiere, el límite de intercambiabilidad del producto del trabajo de alguien, es el mundo entero. La mercancía instaura un tipo de universalismo social que articula a las personas por encima de los parentescos, los países, los Estados y los continentes; "mi producto —anota Marx — sólo es producto para mí en la medida en que lo es para otro, es, por lo tanto, un individual superado, un universal" (1978: 208). Sin embargo, se trata de un universalismo abstracto porque el vínculo con el resto de los habitantes del mundo susceptibles de realizar el "valor de uso" del objeto, solo se puede realizar a través de otra abstracción universalizante, el trabajo abstracto contenido en la mercancía, el "valor de cambio".

Si bien la mercancía en su realización proyecta el espacio territorial mundial como el espacio de su realización de intercambiabilidad, lo hace guiado, o dominado, por otra abstracción de carácter igualmente universal y abstracto: el tiempo de trabajo abstracto depositado en la cosa, en el producto, en la mercancía, es decir, el valor de cambio. Solo si sus potenciales poseedores, los habitantes del mundo, concurren al intercambio portando un cuerpo de utilidad, o un símbolo (dinero), equivalente al monto de trabajo abstracto depositado en la mercancía deseada, entonces podrán acceder a la posesión de la mercancía y usarla. En caso contrario, esta realización será negada.

$\mathrm{Y}$ en la medida en que la cantidad de trabajo abstracto, el valor de cambio, sea la clave para proceder al acceso a la mercancía, la intercambiabilidad no depende ni de parentesco, ni de nacionalidad, ni del idioma ni de la proximidad cultural; sino solo de poseer el equivalente de esa cantidad de trabajo depositada en algún otro cuerpo material necesario (trueque), o de equivalencia general (el dinero), que habilita inmediatamente la compra venta de mercancías. Y como se trata de un vínculo fundado en una cantidad de trabajo humano general, una cualidad universal y abstracta de la actividad humana independientemente del lugar de las personas, entonces, el espacio de potencialrealización territorial de la mercancía queda nuevamente redondeado planetariamente. En este sentido, en la medida en que el mundo es el espacio de realización de este tipo de intercambiabilidad basada en una abstracción universal (el monto del trabajo social), entonces la territorialidad del valor de cambio es el planeta mismo o, si se prefiere, la globalización. Lineamientos fundamentales para la crítica de la economía política.

Esto marca una diferencia absoluta de la sociedad capitalista con respecto a todas las otras sociedades que nos han precedido. Los ámbitos de realización territo- 
rial del producto del trabajo en una comunidad pueden ser la familia, en lo fundamental; las relaciones y los vínculos de parentesco en lo principal, y solo de manera esporádica, tangencial o secundaria las comunidades aledañas, las comunidades más alejadas.

Cuadro 1. Génesis del espacio nacional y el espacio global del capitalismo

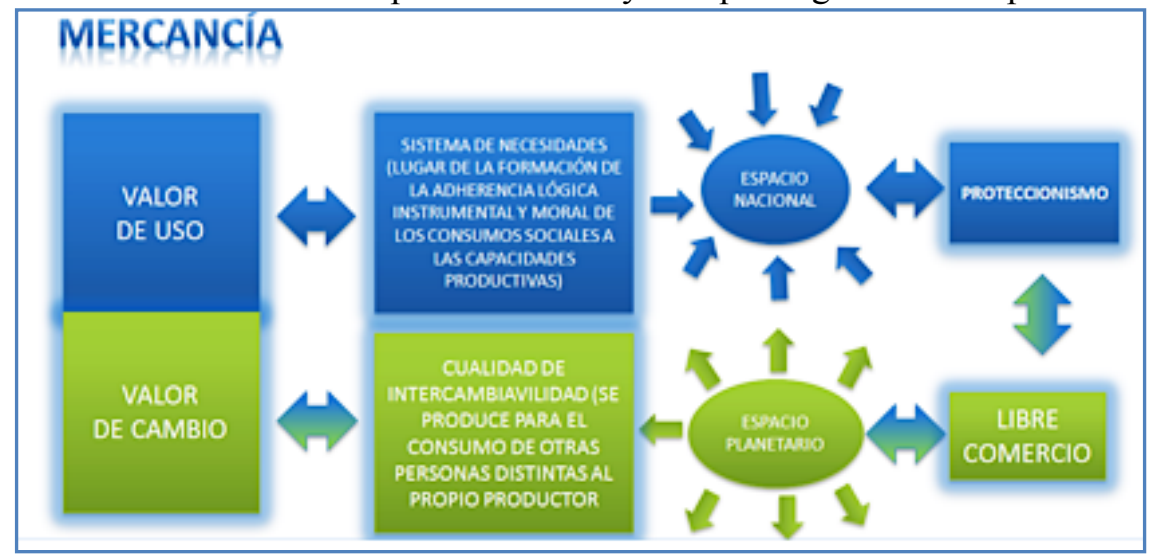

Fuente: Elaboración propia.

Resumiendo, en la célula de la sociedad moderna, la mercancía, como lógica y proceso social, se encuentran contenidos los dos espacios territoriales de la constitución de la sociedad moderna. La mercancía, en tanto valor de uso, habilita preferentemente el espacio nacional como el espacio de constitución de las necesidades, de la cultura, de la cohesión y de la legitimación o modo específicamente capitalista de construcción de los esquemas morales, de los esquemas lógicos, de los esquemas procedimentales e instrumentales de las personas. Y, por otro lado, la mercancía, en tanto valor de cambio, habilita como espacio de realización de la intercambiabilidad del valor-trabajo que contiene al espacio-mundo, al espacioplaneta como el lugar de la realización final de la mercancía.

Los distintos modos de producir la riqueza han tenido una forma de definir el espacio geográfico de su realización. La forma mercancía, es decir, el núcleo organizativo del capitalismo, nace, simultáneamente, con la constitución de dos espacios: el espacio de la necesidad - que es un hecho cultural, es un hecho lógico y práctico-y el espacio de la intercambiabilidad — que es, por definición, universal, planetario-.

El capitalismo nace cabalgando simultáneamente dos espacios, dos geografías sociales, dos territorialidades: la geografía nacional y la geografía planetaria; dimensión geopolítica nacional de la mercancía y la dimensión geopolítica planetaria universal de la mercancía.

\section{Proteccionismo y libre comercio}

Esto explica por qué, a lo largo de la historia del capitalismo, desde hace más de 500 años, en sus distintas variantes cíclicas e históricas — ya sea bajo hegemonía 
de los Países Bajos, luego con hegemonía inglesa, después norteamericana (Arrighi, 1999) - , el desarrollo del mundo capitalista ha intercambiado en cada ciclo sistémico, momentos de predominio de políticas proteccionistas centradas en el mercado interno, barreras arancelarias, regulaciones laborales locales, etc., y momentos de supremacía del liberalismo económico, apertura planetaria de mercados, desregulaciones laborales, financiarización de la economía, etc.

El proteccionismo prioriza la protección de la industria nacional, la regulación de los flujos financieros, la vinculación selectiva con otros mercados nacionales, la sustitución de importaciones y, en definitiva, la densificación capitalista del espacio nacional. No se trata de la formación de espacios autárquicos, pues los flujos comerciales mundiales objetivamente articulan las distintas actividades nacionales; pero este mercado mundial y esta economía mundializada desde hace más de 500 años se la hace a partir del espacio nacional como célula. En ese sentido, el mundo capitalista se presenta como una articulación flexible de espacios nacionales capitalistas.

Pero, a la vez, el otro espacio constitutivo del capitalismo moderno es el valor de cambio, y hemos asociado el valor de cambio a la universalidad. Y esta universalidad del intercambio es el libre cambio. Surge entonces, enraizado en la lógica inmanente de la mercancía y del capitalismo, esta corriente teórica, económica, ideológica, filosófica del libre cambio, o del liberalismo o del neoliberalismo en cuya mirada la preocupación ya no es el espacio interior, no es la geografía interior, no es el horizonte interior de la sociedad. La lógica librecambista, la lógica liberal o neoliberal habrá de centrar su preocupación, sus políticas y sus reflexiones en una mirada del mercado mundial, de los flujos mundiales de dinero, de los mercados financieros planetarios, de las desregulaciones de todo tipo. Por lo tanto, en esa mirada las fronteras nacionales son un estorbo, las culturas nacionales son un estorbo, y de lo que se trata es de crear un único espacio homogéneo de universalidad de la mercancía del capital.

Bajo esta lógica no es que la dimensión nacional desaparece. Aun hasta hoy, no existe un espacio o unas institucionalidades capaces de sustituir a la del Estadonación en la construcción de las adhesiones lógicas y morales a la forma mercantil de la producción y de la sociedad. Pero, además, el liberalismo económico en los hechos funciona como la imposición mundial de la lógica económica, de la necesidad de nuevos mercados de la producción y las finanzas del Estado-nación hegemónico mundialmente. Y en este derrumbe de fronteras se juega la continuidad y el éxito de ese Estado capitalista hegemónico. Pero lo que lo diferencia de la territorialidad planetaria bajo el liberalismo económico es que, ese espacio planetario de irradiación de la potencia hegemónica pre-existe y regula la presencia y densidad de los espacios nacionales.

En el proteccionismo el espacio mundial capitalista se presenta como la suma articulada de espacios nacionales. En el liberalismo, el espacio planetario se presenta como anterior e independiente de los espacios nacionales, cuya existencia opacada se la soporta como necesaria para disciplinar, cultural y coercitivamente, a las clases populares.

Ambos momentos históricos requieren del espacio nacional y del espacio planetario para desplegar en su interior el desarrollo de la modernidad capitalista. Pero lo que los diferencia es el predominio de uno de los espacios en la constitución del 
otro. Siempre estarán interactuando los dos, el nacional y el mundial. Pero bajo el proteccionismo, no solo el espacio nacional es el que sobresale, sino que el espacio planetario está constituido a partir de los espacios nacionales. En el momento de libre cambio, el espacio planetario es el que predomina y además es el que forma el espacio nacional como lugar contingente de cohesión y adherencia social.

El capitalismo, entonces, desde su propio fundamento, nace con una tensión insuperable. Mientras haya capitalismo, habrá de haber esta tensión entre la dimensión del espacio nacional y la dimensión del espacio planetario. En momentos, uno de esos espacios, el nacional será el predominante; en otros momentos, el espacio planetario será el predominante. Pero en ninguno de los casos uno hace desaparecer al otro. Si bien parecen como antagónicos, en realidad se necesitan mutuamente.

Se puede decir, por tanto, que, en términos generales, la narrativa histórica de la economía capitalista tiene dos grandes vertientes; el proteccionismo (con múltiples variantes) y el liberalismo (con múltiples variantes). En los momentos en que predomina el proteccionismo (1930, después de la crisis de la bolsa de 1929), hasta los años 1970, son tiempos de expansión de los mercados nacionales, ampliación de derechos sociales que en el caso de los Estados Unidos y Europa dieron lugar al Welfare State que duró hasta los años 1980; y en el caso de América Latina a las políticas de sustitución de importaciones. Pero, aun en los momentos más intensos de proteccionismo, también estará presente una dimensión planetaria de otros flujos económicos, como los flujos tecnológicos, financieros y una división internacional del trabajo (países que producen la materia prima, países que procesan la materia prima, países que hacen productos intermedios y países que generan tecnología de punta).

Lo mismo con la lógica del libre comercio. Si bien en la lógica liberal existe una predominancia del espacio planetario como escenario de circulación del capital financiero, como espacio de circulación de las industrias transnacionales, hay una función necesaria e imprescindible del espacio nacional, del Estado nacional. Pongamos el caso de Brasil, el caso de Bolivia o el caso de Argentina, que han sido objeto de políticas neoliberales durante los años 80,90 y ahora nuevamente en el caso de Brasil y de Argentina. ¿De dónde parten las decisiones y la capacidad operativa que regula la supresión de derechos o para establecer flexibilidad laboral? No son los mercados financieros, no es la "nube imperial" que imagina Toni Negri recorriendo el mundo. Es el Estado nacional, son sus mecanismos de generación de leyes, sus mecanismos coercitivos, los medios de comunicación, que generan consensos y tolerancias morales frente a estas decisiones. ¿Quiénes son los entes que privatizan los recursos colectivos de la sociedad? Los Estados nacionales. ¿Quiénes son los que van a disciplinar a las clases peligrosas o a las clases sublevadas en cuanto a esas políticas? Los Estados nacionales, sus mecanismos de coerción, sus mecanismos de legitimación.

Es decir, aún en el momento de mayor predominancia de un neoliberalismo desbocado, el único sujeto que tiene una función conductora, una función reguladora y disciplinadora de la fuerza laboral para imponer el libre comercio, es el Estado nacional. Pero, además, a la par que el Estado desempeña la función de adecuar el universo de expectativas sociales al universo de posibilidades económicas en cada espacio territorial, también profundiza y radicaliza la jerarquización territorial de la distribución internacional de la riqueza y la pobreza. El último informe de Oxfam 
(2017) habla de que el $1 \%$ de la población mundial y que habita en el norte ostenta el $50 \%$ de la riqueza del mundo; y que una sola persona tiene más riqueza que diez naciones juntas. El neoliberalismo ha vuelto a reterritorializar la riqueza, es decir, ha vuelto a definir espacios de concentración de la riqueza y espacios de extracción de la riqueza.

Cuadro 2. Proteccionismo y libre comercio

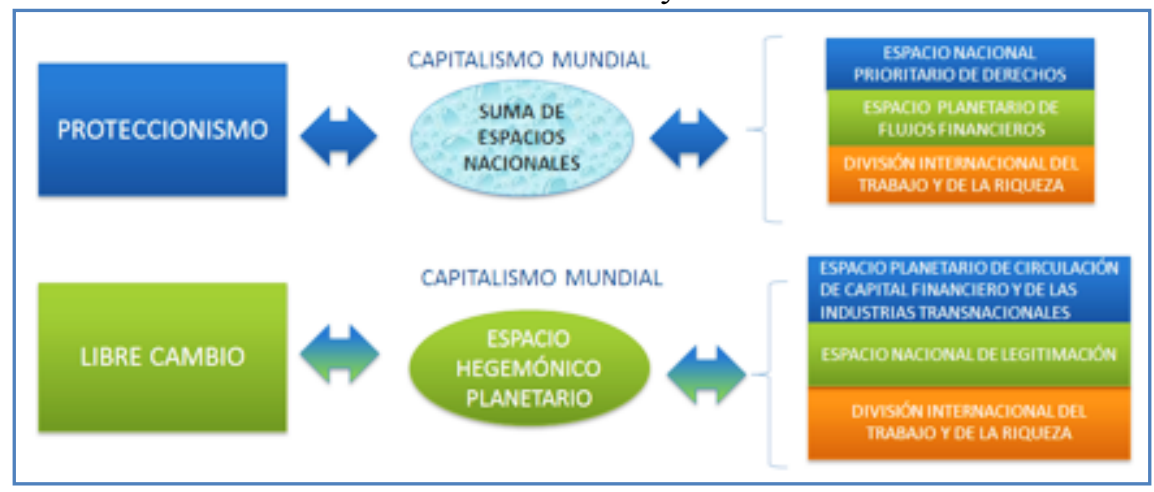

Fuente: Elaboración propia.

Entonces, las dos corrientes de desarrollo e interpretación del capitalismo contemporáneo desde hace 500 años son el proteccionismo y el libre comercio, que han tenido cada una oleadas de predominio y de repliegue: proteccionismo, libre comercio; proteccionismo nuevamente, luego libre comercio, etc. Y a pesar de esas diferencias, ninguna anula a la otra. Así como en el capitalismo el valor de uso no anula el valor de cambio ni el valor de cambio anula el valor de uso, sino que ambos cabalgan el flujo de la riqueza y de las mercancías en el capitalismo. Cuando el proteccionismo predomina sobre el libre comercio, hay aspectos del libre comercio y del espacio planetario que se mantienen. Y en los momentos del libre comercio, si bien predomina el espacio planetario como escenario de la acumulación del capital, hay una presencia de los Estados nacionales como los espacios de regulación cultural de la fuerza de trabajo, de disciplinamiento social, de cohesión, castigo y adecuación moral de los dominados hacia los dominantes vía políticas estatales.

Entonces, el proteccionismo se presente como la territorialidad delimitada de derechos. El proteccionismo habla de anclar el espacio nacional, el Estado-nación, como el espacio de la constitución de los derechos frente a otros espacios nacionales de derechos. En tanto que el libre mercado habrá de buscar al universo, al mundo entero, a la geografía planetaria entera, como un espacio de homogeneización planetaria de oportunidades y realizaciones.

Cada una de estas narrativas tiene una utopía que al final resulta fallida. La lectura proteccionista del espacio concibe al mundo como una suma de espacios nacionales, uno al lado del otro y, entonces, el mundo capitalista, será la articulación negociada de las relaciones de estos sujetos llamados Estados-nacionales. La globalización en el proteccionismo vendría a ser, entonces, un resultado flexible y contingente de los acuerdos establecidos entre estos espacios nacional-estatales. Se trata de una utopía fallida, porque en realidad por la naturaleza misma de la mercancía cuyo espacio de intercambiabilidad es planetario, hay un conjunto de rela- 
ciones económicas que se han ido construyendo al margen de los Estados, por encima de los Estados, como el patrón de intercambiabilidad mundial; la plata en el siglo XVII, XVIII; la libra en el siglo XIX, el oro y el dólar en el siglo XX; o la lógica de los mercados financieros, o la división del trabajo y el eslabonamiento de las cadenas productivas, etc.

Por su parte, la utopía liberal o neoliberal imagina al mundo como un espacio mundial homogéneo donde todos somos aparentemente iguales; donde ya no existen barreras ni reductos culturales que diferencien a los países y donde todos somos consumidores o productores, o empresarios, o emprendedores, sin diferencia alguna. Pero esta utopía también resultara fallida porque hasta hoy, la sociedad moderna no conoce otra manera de construcción simbólica del mundo con capacidad de hegemonía cultural duradera, que no sea la de la adhesión territorial y la agregación política territorial de los Estados. Y es alrededor de este hecho de fondo que cualquier globalización irá diferenciando territorialmente bienes, oportunidades, recursos y jerarquías que desdibujan la homogeneidad imaginada y la develan como un espacio escindido, jerarquizado y dividido territorialmente.

Una variante izquierdista de este utopismo globalizador es la teoría de Michael Hardt y "Toni” Negri (2002) sobre el Imperio. En el fondo es una extrapolación de la lógica liberal, de la homogeneización del espacio, llevada hasta el extremo. Conciben al mundo como un espacio único donde ya no existe ni centro ni periferia, porque en el antiguo centro, dicen ellos, hay también periferia. Es decir, en Nueva York, en París o en Londres hay también la periferia, la miseria de la periferia. Y donde la antigua periferia (Bolivia, Brasil, Singapur, México, Filipinas, Sudán y otros) también tienen pedazos del centro. Así, el mundo hubiera encontrado un espacio de homogeneización que ya no tiene centro, porque el centro está en todas partes, y la periferia está en todas partes; y entonces la posibilidad de imaginar los sujetos y los territorios de emancipación, la multitud, carecería de referencia o anclaje espacial pudiendo ser todos en todas partes y por encima de sus antiguas pertenecías y referencias clasistas, nacionales e identitarias.

Lo erróneo de esta sofisticada construcción mental es que las actuales luchas en el "Imperio", en plena globalización, en Europa, América Latina y Estados Unidos ni por un instante han perdido su referencia territorial, nacional, ni han eludido como objeto de interpelación y movilización las estructuras estatales de dominio. Grecia, New York, La Paz, Sao Paulo, Buenos Aires, Madrid como emblemas de las sublevaciones del nuevo siglo, no lo han hecho contra una "nube" imperial que está en todas partes; lo han hecho enfrentando determinadas políticas de gobiernos territoriales; desobedeciendo determinadas acciones de instituciones y mandantes territoriales. Y, lo irremediable, lo han hecho evocando memorias históricas territorialmente ancladas; articulando símbolos y referentes movilizadores de eficacia territorial; y el horizonte de esperanza gatillado ha sido en torno a nuevas formas de democratización social en el territorio delimitado estatalmente y articulando sujetos sociales con ese fin de decisión territorial.

Y no se puede argüir que la "multitud" actúa equivocadamente o que apela, melancólicamente e inútilmente, a viejas formas (territoriales), en un mundo finalmente desterritorializado, porque estaríamos recayendo en las añejas e impotentes argucias de los "reformadores" de academia que, ante la incongruencia de sus especulaciones con respecto a la realidad, consideraban que era la realidad la que 
se había extraviado y que, tarde o temprano, esa realidad se iba a adecuar a la "brillante" teoría.

Es que la utopía globalizadora de los defensores del libre comercio en realidad es una farsa, una ilusión que solo ha servido para legitimar las profundas diferencias, jerarquías y dominaciones territorialmente organizadas que se han intensificado durante el periodo de oro de la llamada globalización.

Veamos algunos datos.

\section{Los abismos espaciales de la riqueza y el poder en la globalización}

Viendo los datos de la densificación geográfica, de las inversiones de capital, de los flujos monetarios, de la densificación geográfica del transporte, de los conocimientos, de las tecnologías, lo que se ve inmediatamente es que las empresas que invierten sus capitales en otras regiones del mundo están en Norteamérica, en Europa y en China, y estas zonas son también las receptoras principales (Figura 1).

Figura 1. Principales receptores de Inversiones Extranjeras Directas (2010)

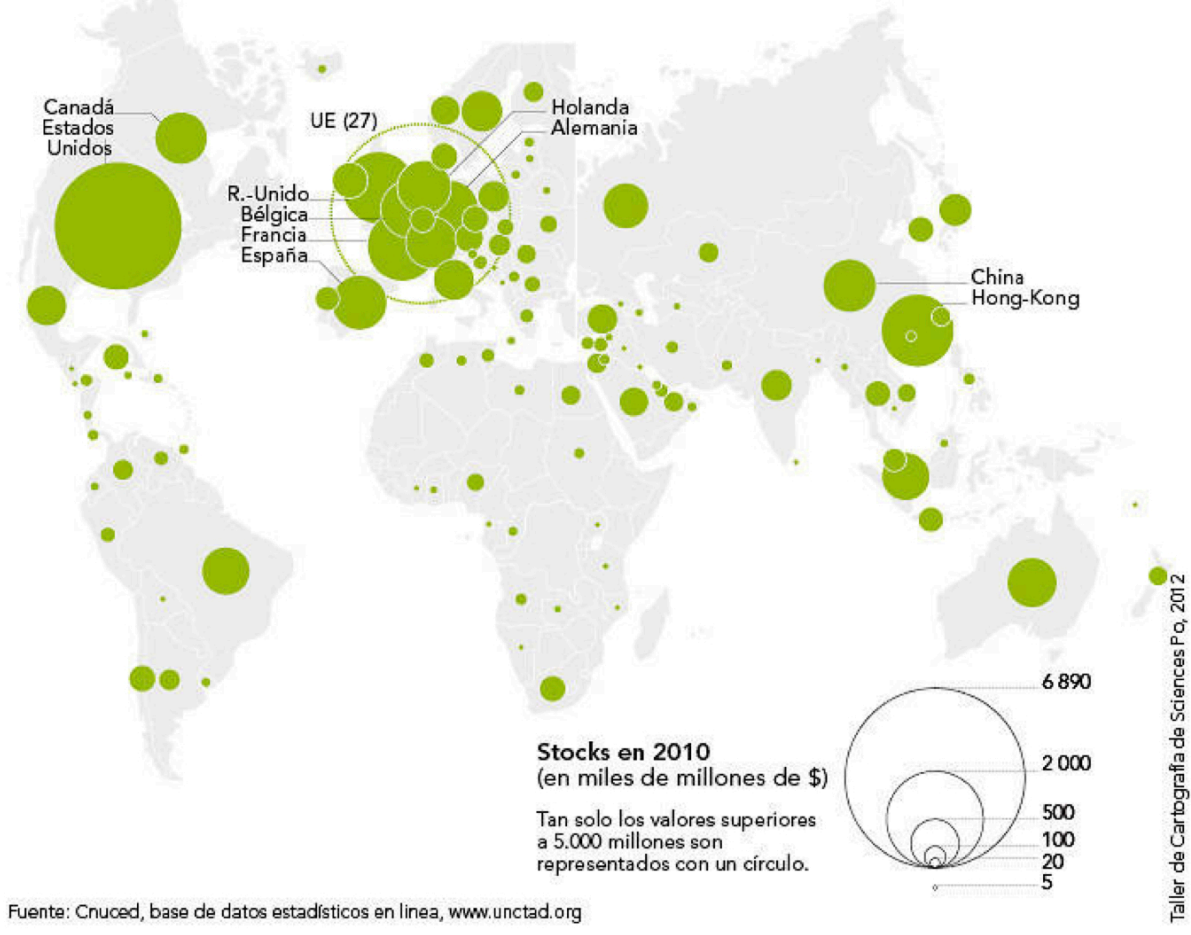

Fuente: FNSP. Science Po - Atelier de cartographie, 2012.

La mayor parte del transporte aéreo mundial está concentrado no sólo en el Norte, sino en la parte oeste de Asia, en este eje que va del Pacífico y el Atlántico en el norte. América Latina, Asia, África, parte de Europa y Asia del Norte y Oceanía quedan más marginadas. Con el transporte de pasajeros pasa lo mismo, los flujos 
migratorios mundiales van de América Latina hacia Estados Unidos, de África hacia Europa, parte de Europa hacia Estados Unidos, Asia hacia Europa, Asia hacia Estados Unidos. Van de los países pobres a los países ricos, porque hay una geografía planetaria de la riqueza y la pobreza.

Figura 2. Riqueza y pobreza de los Estados en el año 2014

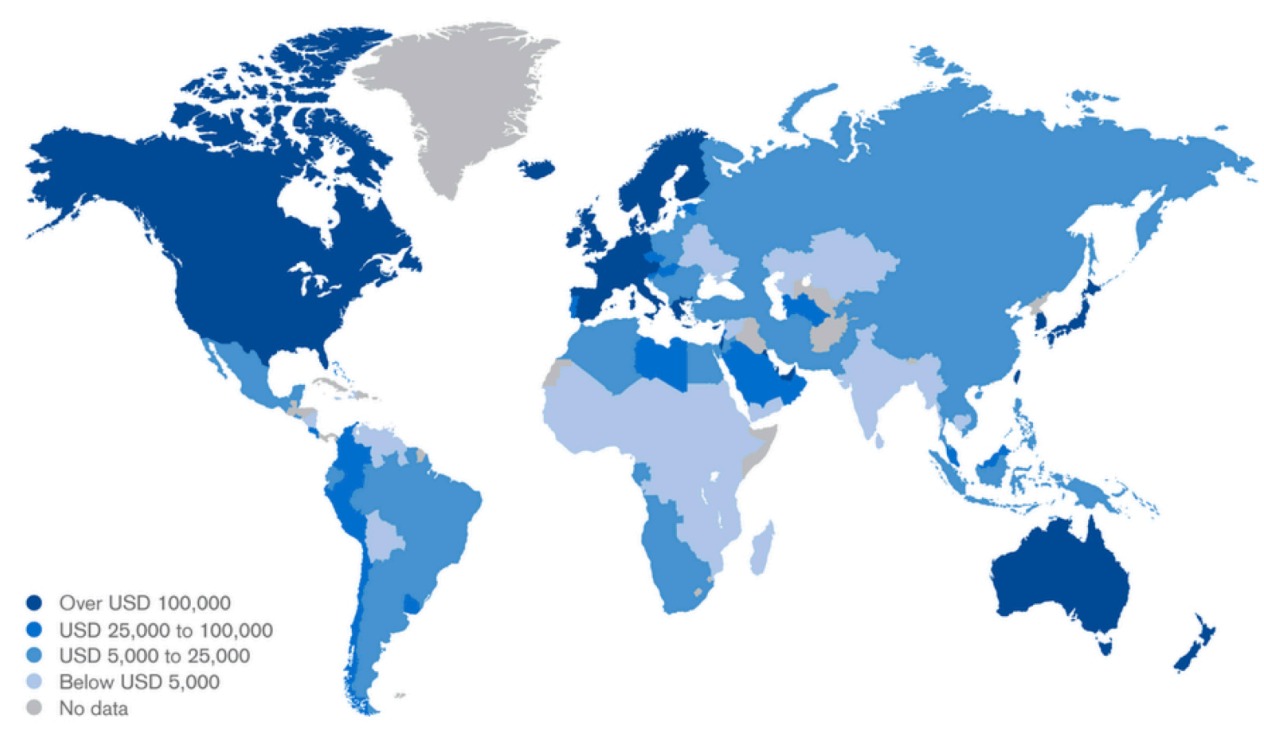

Fuente: The Global Wealth Report 2016. Credit Suisse ${ }^{3}$.

E1 $91 \%$ de la riqueza concentrada en los países más ricos, $6 \%$ de la riqueza en los países intermedios, $1 \%$ de la riqueza de los países de ingresos medios y el 0,07 $\%$ de la riqueza en los países más pobres que son la mayoría. La riqueza y la pobreza también tienen una dimensión geográfica (Figura 2). No estamos ante una homogeneización de los recursos, de las tecnologías, de las riquezas, como imagina la utopía liberal y como en cierta medida imagina también la versión más izquierdista, postmoderna, de esa interpretación.

Si consideramos el transporte de residuos atómicos del mundo, Estados Unidos es el mayor productor, pero los países que reciben más residuos están en el sur. Si vemos el mapa de los horizontes de posibilidades de la juventud, los países europeos están súper inflados, África está súper achicada y en muchos lugares del Sur global es imposible pensar en un lugar de desarrollo, de bienestar para ellos.

Si observamos la distribución de la inversión en presupuesto militar, tenemos un sur carente de inversión en tecnología militar y un norte con una gigantesca inversión en tecnología militar. La inversión en presupuesto militar no solo produ-

3 Ver URL: <https://www.credit-suisse.com/corporate/en/articles/news-and-expertise/the-global-wealth-report2016-201611.html>. Consultado el 13 de octubre de 2017. 
ce armas, sino, que también, tecnología de punta que luego es apropiada por las empresas civiles. El internet fue una herramienta militar que después se ha convertido en herramienta civil. Y muchas otras de las tecnologías que utilizamos en los celulares, en los televisores, vienen de la ingeniería militar que luego son recicladas y reutilizadas para el consumo civil.

El comercio mundial está concentrado en Europa, Estados Unidos y China. De hecho, este flujo (Norteamérica, Europa, Asia, se incluye a Japón, a China, Corea del Sur, Singapur, entre otros) absorbe el $70 \%$ del comercio mundial (Figura 3).

En lo que se refiere a la transferencia neta de deuda, ésta resulta comparando el dinero recibido de crédito por un país y el dinero que sale de ese país por concepto de pago de intereses y de deuda. Lo que lleva a que cuando anualmente sale más dinero de un país que el que recibe de crédito, hablamos de un saldo negativo; y el saldo negativo es para América Latina, para África, para Medio Oriente, para los antiguos países socialistas de Europa Oriental, para India y para Australia.

Figura 3. Comercio mundial de mercancías (2010)

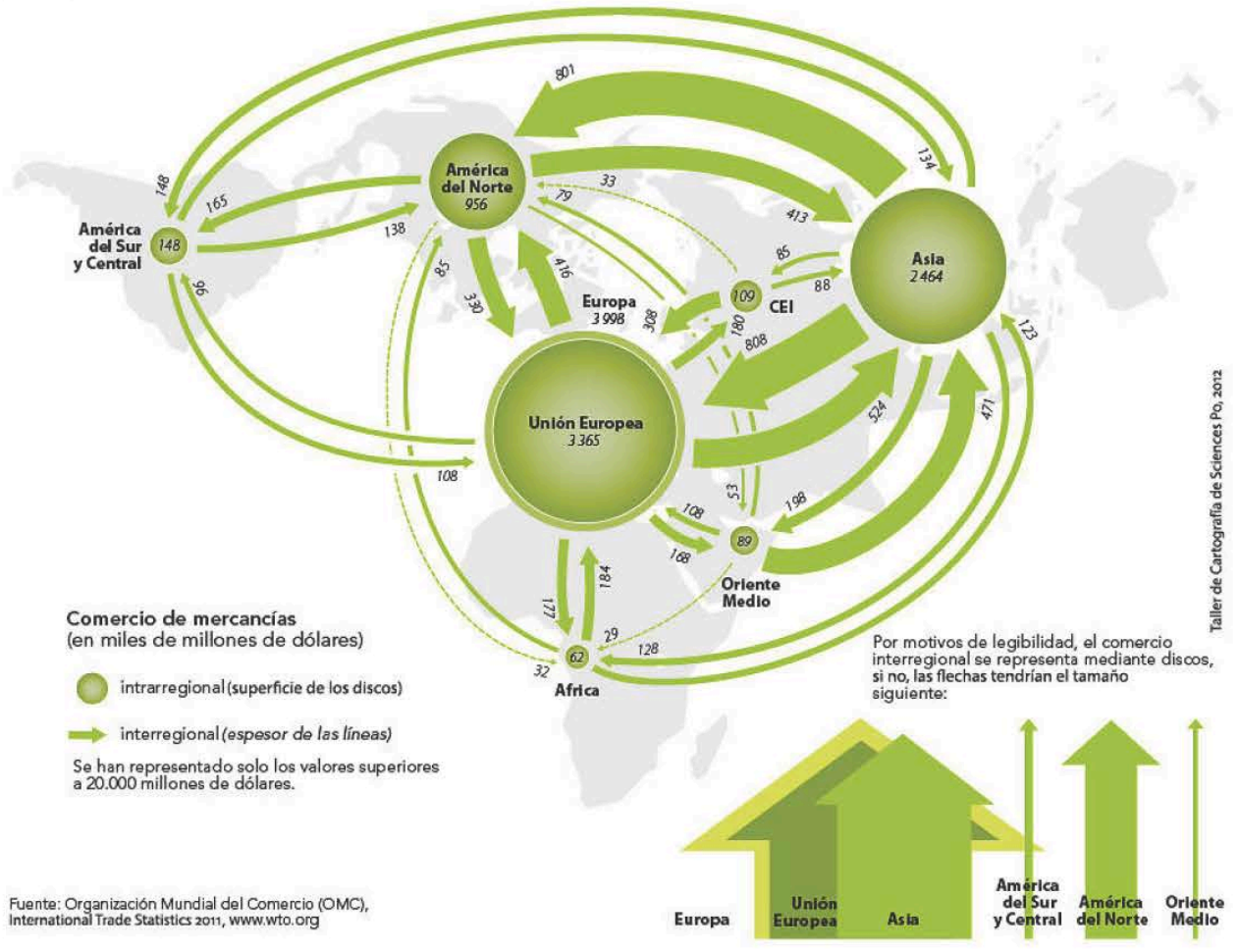

Fuente: FNSP. Science Po - Atelier de cartographie, 2012.

Por último, veamos la relación entre el Producto Interior Bruto respecto a la población. En el mapa, los lugares con mayor PIB per cápita tenemos la existencia de condiciones para la satisfacción de condiciones materiales básicas de la población. Y ello solo sucede en el norte (Estados Unidos, Canadá, Europa y Japón). En América Latina, la relación es mucho más baja; en África está desproporción es aún mayor, al igual que en el Sudeste Asiático y China. 
Figura 4. Producto Interior Bruto por Estado y por habitante (2010)

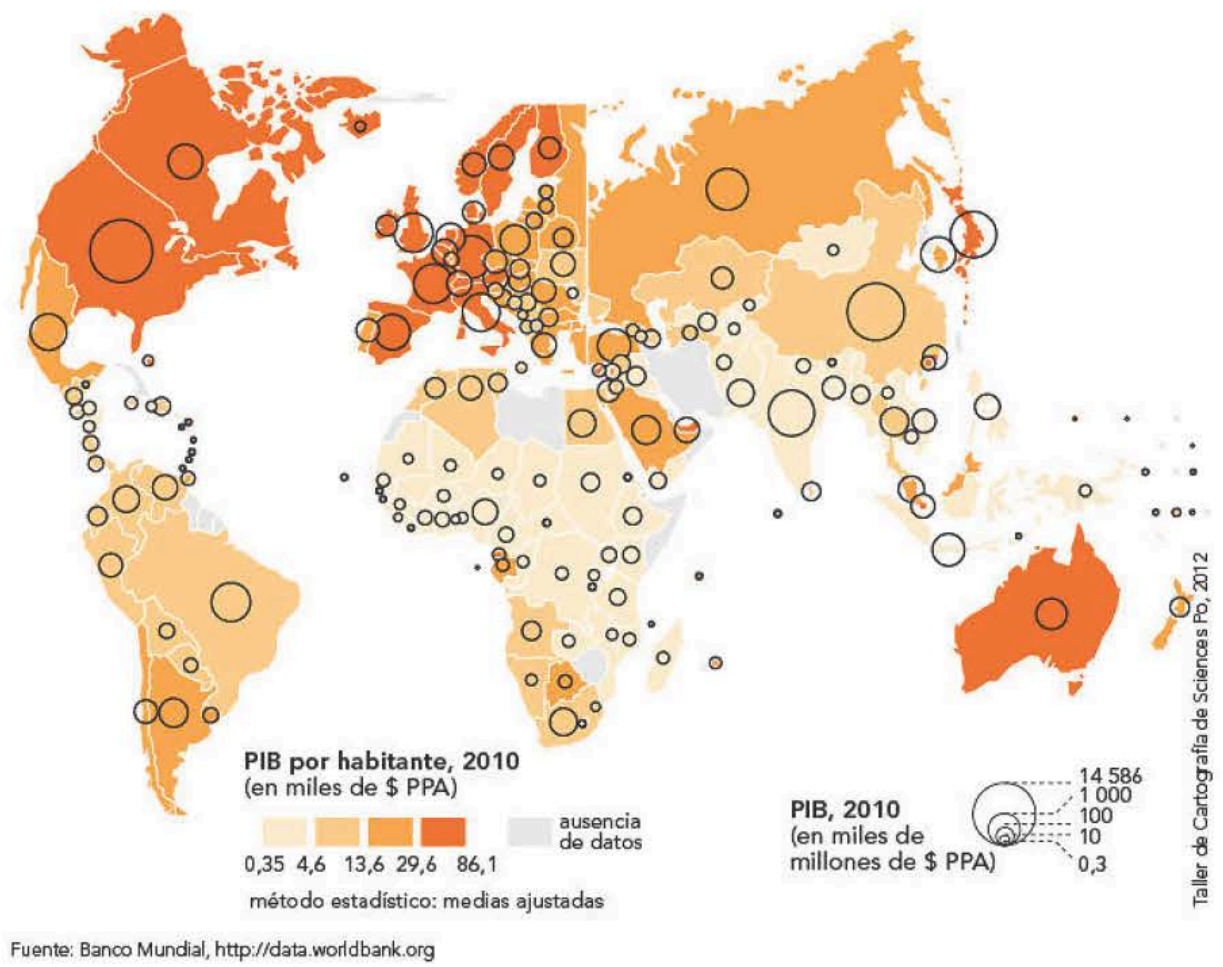

Fuente: FNSP. Science Po - Atelier de cartographie, 2012.

¿Qué muestran estos datos? Que la geografía planetaria de la globalización no es homogénea. Que esa es una ilusión. Lo que ha hecho el liberalismo es reproducir e intensificar una distribución geográfica ultra jerarquizada de la riqueza, de las tecnologías, de los poderes financieros, de los poderes militares, del comercio, del transporte y del consumo. Así como el mundo no es una suma de Estados nacionales, porque hay una dimensión transestatal de relaciones económicas, tampoco es un espacio plano y uniformizado de recursos y oportunidades.

Hay, pues, una distribución geográfica de las riquezas y las pobrezas; hay una segregación geográfica de las tecnologías y los conocimientos; hay una jerarquización de unas geografías sobre otras. Y esto tiene tal dimensión que, en ciertas circunstancias, tiene la función de un bucle. Es decir, que se retroalimenta: a cierto nivel de riqueza, esa riqueza ha de convocar a más riqueza, y esa nueva riqueza a mucha más riqueza. Y a cierto nivel de pobreza, esa pobreza ha de convocar a más pobreza.

Pareciera ser que el mundo, en determinadas circunstancias, funcionara con cierto automatismo en cuanto a la concentración territorial de oportunidades y a la carencia material de recursos, de oportunidades, de riquezas, de tecnología y de comercio. 


\section{La organización espacial del capitalismo: la crisis del neoliberalismo}

La segunda hipótesis que manejo hoy es que el ciclo neoliberal ha entrado en crisis. Es un momento de transición histórica. Mi hipótesis se basa en tres datos específicos: primero, la salida de Inglaterra de la Unión Europea (el Brexit), lo que significa un retraimiento hacia el mercado interior de Gran Bretaña, desprendiéndose de este esfuerzo de crear un único espacio comercial europeo.

El segundo dato es que por segundo año consecutivo (2015 y 2016), el comercio mundial ya no ha crecido a la misma velocidad a la que lo hacía anteriormente. Antes, los últimos cinco años, el comercio crecía entre el 50 y el $100 \%$ por encima del crecimiento de la economía real de la producción. Los últimos dos años el comercio se ha estancado y ha crecido menos que la propia economía real, es decir, los mercados han encontrado un freno en estos dos últimos años mostrando que hemos llegado a un momento de transición, de crisis de la lógica de la acumulación y de la circulación de las mercancías en el mundo que habían predominado los últimos 30 años de libre comercio.

$\mathrm{Y}$ el tercer dato es el triunfo de Donald Trump en Estados Unidos, que, de manera abierta, ha establecido una política proteccionista para Norteamérica, a contramarcha del decálogo neoliberal que había caracterizado a sus predecesores desde Ronald Reagan en 1980. Trump ha retirado a Estados Unidos del Acuerdo Transpacífico de Cooperación Económica que pretendía unir en la lógica del libre comercio a todas las economías que acordonan el océano Pacifico. Está renegociando el Tratado de Libre Comercio con México y Canadá, recortando lo más que se pueda las facilidades a las exportaciones de sus vecinos amigos; ha amenazado a empresas norteamericanas que quieran deslocalizar sus industrias a otros países con salarios más bajos. Y ha de construir un largo y amenazante muro en su frontera sur para impedir que los latinos "quiten" puestos de trabajo a los norteamericanos.

Estamos, por tanto, ante un conjunto de agresivas políticas proteccionistas que quiebran la antigua narrativa neoliberal con la que Reagan y la primera ministra del Reino Unido, Margaret Thatcher, inundaron el mundo y que anunciaban que el libre mercado no solo era la salvación del mundo sino el destino final de toda la humanidad. Y ahora, cuando casi todos se habían creído el cuento del "fin de la historia" resulta que quienes inventaron ese cuento, Estados Unidos e Inglaterra, le dicen al mundo que la historia no acaba con la globalización y que ahora es mejor proteger el mercado nacional. Paradójicamente, quienes ahora defienden con gran esmero el libre comercio son los comunistas de China.

A esto es que se puede llamar el fin de la utopía política neoliberal. No es que la globalización económica vaya de desaparecer. Los flujos comerciales, los mercados financieros habrán de mantenerse, quizás más lentos, quizá más recortados, pero el espacio planetario como escenario de la realización del dinero habrá de continuar. Sin embargo, lo que sí ha muerto es la ideología de la globalización; lo que sí se ha derrumbado es la ideología, la farsa, la ilusión, de que el libre comercio mundial era el destino final de la humanidad (Fukuyama, 1992).

Una vez derrotada la Unión Soviética como opción social, ¿qué le quedaba al mundo?, neoliberalismo, libre comercio, globalización, privatizar; ese fue el discurso que difundían partidos políticos, los medios de comunicación, los centros de investigación, los comentaristas, los izquierdistas arrepentidos, el sentido común de 
la sociedad. Hoy, con Trump, el Brexit, la caída del comercio mundial y el regreso de políticas proteccionistas muestran que la globalización neoliberal, como ideología política, ha muerto.

No es el fin de la globalización de mercados ni de la globalización de los flujos comerciales, no, es una ralentización de eso; pero, sí es la muerte de la ideología, de la utopía, del proyecto político.

Lo que queda es una incertidumbre general, un extravió, una saludable y liberadora pérdida del sentido único de la historia. Liberadora porque la ideología globalizadora imponía la impotencia social, la resignación ante el "ineluctable destino". Hoy no hay destino, por tanto, lo que vaya a suceder ha de depender de lo que la sociedad misma haga, lo que su desesperación o sus esperanzas renacidas lo permitan. Finalizado el "fin de la historia", la historia vuelve a recomenzar.

Es, por ello, un excepcional momento de transición, es un momento de "incertidumbre caótica", a decir de Wallerstein (2009). Es un momento de reacomodo de las ideologías, de los proyectos políticos, es decir, de la disputa por el monopolio de la administración de las esperanzas. Pero también es un momento de reacomodo de la función geográfica de la acumulación capitalista, ha de haber un reacomodo del uso de la geografía en función de la acumulación; ha de haber un reacomodo de la prioridad, de la importancia de los distintos espacios geográficos en la nueva ruta que tomará para delante la acumulación capitalista, $y$, por supuesto, ha de haber una intensificación de los desequilibrios, de las desigualdades territoriales, de las desigualdades geográficas, en cuanto a riqueza, a tecnología, a comercio y en cuanto a oportunidades.

\section{Conclusiones y reflexiones de futuro}

Ahora, la pregunta que uno se hace es: ¿cómo ha de afectar todo esto a la geografía de las resistencias sociales? Porque también la resistencia tiene una dimensión geográfica. No es que la geografía genere la resistencia, es la sociedad la que genera resistencia, pero la geografía potencia las resistencias. La geografía, la composición geográfica de un país, de una región, la composición geográfica, natural, geológica de una región, favorece y potencia las acciones colectivas.

Pongo un ejemplo, aquí en Bolivia, el caso del movimiento campesino cocalero del Chapare, de donde viene el presidente Evo, fue la estructura social más movilizada que se enfrentó al neoliberalismo. Pero, ¿hubiera tenido el mismo nivel de presión el movimiento cocalero si hubiera estado ubicado en el norte de Beni? Evidentemente no. ¿Por qué? Porque en ese espacio geográfico, donde está el movimiento cocalero, es el lugar donde se intercomunican los flujos entre Santa Cruz, que es una región económicamente más pujante con los mercados departamentales e internacionales. Las principales exportaciones e importaciones del país pasaban por el Chapare. Entonces, la capacidad de movilización social en esta región devenía inmediatamente en una capacidad de presión económica que inmediatamente, por la fuerza económica de la geografía, convertía al movimiento campesino cocalero en un movimiento de gravitación e irradiación nacional. Ahí la geografía convirtió la fuerza social en poderío político nacional. 
Este lugar geográfico, esta disposición geográfica, hizo de un movimiento campesino muy bien organizado, muy bien disciplinado, un movimiento con una capacidad efectiva de presión y de veto económico sobre la economía neoliberal. Ahí no fue la geografía la que dio lugar al movimiento social, sino que fue el movimiento social el que se potenció con la cualidad de la geografía.

Lo mismo ha de suceder en el mundo. La geografía de la resistencia planetaria al neoliberalismo, la geografía de los movimientos sociales, la disposición territorial de los movimientos sociales, habrá de tener en la geografía lugares que lo potencien o lugares que lo debiliten. Y ahí recojo finalmente la frase de Marx que decía: "Es natural que en las extremidades del cuerpo burgués se produzcan estallidos violentos antes que en el corazón, pues aquí la posibilidad de compensación es mayor que allí" (1975: 217). Entonces, si fuera cierta esta hipótesis, todavía por un tiempo, los lugares, y de hecho así ha sucedido en América Latina, en la anterior década, los lugares donde hay mayor posibilidad, no obligatoriedad, mayores posibilidades de ruptura de los sistemas de dominación estatales, nacionales, han de ser en primer lugar en las "extremidades del cuerpo capitalista". Aunque eso tiene también una contraparte: no necesariamente la miseria y la pobreza genera rebeldía. Muchas veces, la miseria y la pobreza de las zonas, de las extremidades, de las zonas marginales del cuerpo planetario capitalista, muchas veces eso puede generar tolerancias, aceptaciones y resignaciones a la miseria y a la pobreza.

La clave debe consistir en una combinación de dificultades del cuerpo capitalista para compensar territorialmente sus problemas de acumulación económica con historia, acumulación de historia local, de luchas locales con horizonte, con creencia, con esperanza. Nadie lucha solamente porque es pobre. El pobre ha de luchar en la medida en que cree que su lucha puede ser exitosa, es decir, ha de luchar también porque tiene una esperanza, porque se aferra a una idea movilizadora y unificadora. Esperanza más historia de organización más disposición geográfica puede ser una fórmula que habilite espacios de mayor resistencia y de mayor lucha frente a la lógica de la acumulación.

\section{Bibliografía}

Arrighi, Giovanni (1999 [1994]) El largo siglo XX. Madrid: Ediciones Akal.

Fukuyama, Francis (1992 [1992]) El fin de la historia y el último hombre. Barcelona: Planeta.

Hardt, Michael, \& Negri, Antonio (2002 [2000]) Imperio. Barcelona: Paidós.

Marx, Carlos (1978 [1857-8] Elementos fundamentales para la Crítica de la Economía Politica (Grundrisse) (Obras Completas de Marx y Engels, OME, tomo XXI, t. 1). Barcelona: Editorial Crítica.

Marx, Carlos (1975 [1848]) Las luchas de clases en Francia de 1848-1850. En Obras Escogidas de Marx y Engels, t. I. Madrid: Editorial Ayuso.

Marx, Carlos (1987 [1873]) El capital (t. 1, vol. 1). México: Siglo XXI Editores.

Oxfam (2017) "Una economía para el $99 \%$ \%. Informe de Oxfam [Puesto en línea en enero de 2017.2 URL:

$<$ https://www.oxfam.org/sites/www.oxfam.org/files/file_attachments/bp-economy-for99-percent-160117-summ-es.pdf $>$. Consultado en septiembre de 2017]. 
VV AA (2009) El Atlas Geopolítico 2010 de Le Monde Diplomatique en español). Madrid: Akal.

Wallerstein, Immanuel (2009) "El sistema que salga de la crisis será muy diferente". Diagonal [Revista electrónica], núm. 96 [URL: <http://www.diagonalperiodico.net/Elsistema-que-salga-de-la-crisis.html $>$. Consultado en noviembre de 2016]. 